\title{
Reply to Letter to the Editor: Inadequate methodology renders results on the use of tranexamic acid inconclusive
}

\author{
Takao Iwai • Shigeyoshi Tsuji
}

Received: 28 March 2013 / Accepted: 22 April 2013 /Published online: 13 June 2013

(C) Springer-Verlag Berlin Heidelberg 2013

We appreciate the valuable comments and constructive suggestions regarding our paper [1]. We have carefully considered the comments and respond accordingly.

1. We take more time to surgery for TKA because many Japanese patients have severe varus deformity of osteoarthritis.

The surgical haemostasis after tourniquet deflation was performed before placing the polyethylene.

2. Our study has several limitations. The major limitation was the small sample size. Furthermore, the study was not randomised.

3. In our hospital, anaesthetists perform hypotensive anaesthesia in TKA, but do not use hypothermic anaesthesia.

4. In all groups, we used the principles of transfusion based on the guidelines for postoperative surgical patients suggested by the American Association of Blood Banks (AABB). Transfusion was considered at a haemoglobin concentration of $\leq 8 \mathrm{~g} / \mathrm{dl}$ or for symptoms of acute anaemia. In the end, the need for transfusion was decided upon by the orthopaedic surgeon (ST) on the basis of the symptoms of acute anaemia.

5. We stated in our manuscript that the intra-operative blood loss was measured by collected blood and weighed sponges.

6. Administration of TXA twice may eliminate the need for blood transfusion including both autologous donation and postoperative autotransfusion during TKA.
7. This study was not a randomised study. We observed that postoperative autotransfusion was not needed in the single-TXA group (Table 2). Thereafter we started to use TXA twice.

8. We think that the DVT rate of our study was not high [2-4]. Do you mean just symptomatic DVTs? The PE rate of $3 \%$ has developed because of small sample size. (This was stated in "Limitations".)

Finally, we used a higher dose of TXA, and Maniar et al. did not check asymptomatic DVTs. Our study has several limitations, but these should not limit publication in International Orthopaedics.

\section{References}

1. Iwai T, Tsuji S, Tomita T, Sugamoto K, Hideki Y, Hamada M (2013) Repeat-dose intravenous tranexamic acid further decreases blood loss in total knee arthroplasty. Int Orthop 37(3):441-445

2. Yamaguchi T, Hasegawa M, Niimi R, Sudo A (2010) Incidence and time course of asymptomatic deep vein thrombosis with fondaparinux in patients undergoing total joint arthroplasty. Thromb Res 126(4): e323-326

3. Pulido PA, Copp SN, Walker RH, Reden LM, Hardwick ME, Colwell CW Jr (2004) The efficacy of a single daily dose of enoxaparin for deep vein thrombosis prophylaxis following total knee arthroplasty. Orthopedics 27(11):1185-1187

4. Tanaka N, Sakahashi H, Sato E, Hirose K, Ishima T, Ishii S (2001) Timing of the administration of tranexamic acid for maximum reduction in blood loss in arthroplasty of the knee. J Bone Joint Surg Br 83:702-705 